\title{
Research Paper: Marital Satisfaction and Happiness in Parents With Autistic and Normal Children
}

\author{
Hosein Hoseinnejad $^{1}$ (D), Farhad Chopaniyan² ${ }^{\text {(D) }}$, Omid Sarvi Moghanlo ${ }^{3}$ (D), Mohammad Rostami ${ }^{4}$ (D), Asghar Dadkhah ${ }^{*}$ (I) \\ 1. Department of Counseling, University of Social Welfare and Rehabilitation Sciences, Tehran, Iran. \\ 2. Department of Speech Therapy, University of Social Welfare and Rehabilitation Sciences, Tehran, Iran. \\ 3. Department of Psychology and Exceptional Children Education, University of Social Welfare and Rehabilitation Sciences, Tehran, Iran. \\ 4. Department of Counseling, Faculty of Humanities and Social Sciences, University of Kurdistan, Sanandaj, Iran.
}

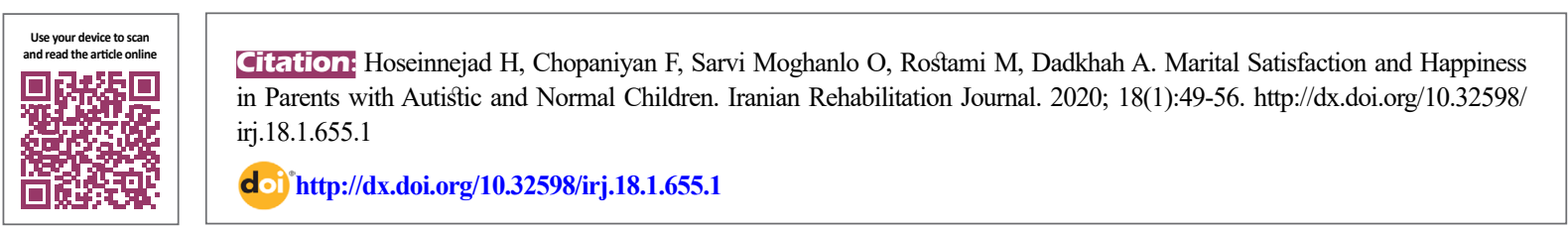

Article info:

Received: 21 Oct 2018

Accepted: 29 May 2019

Available Online: 01 Mar 2020

\section{Keywords:}

Autism, Marital satisfaction, Happiness

\section{ABSTRACT}

Objectives: The present study was conducted to compare the relationship between marital satisfaction and happiness in parents of autistic and normal children.

Methods: This causal-comparative research was conducted on all parents of autistic and normal children who referred to the rehabilitation clinics in Tehran in 2017. Using available sampling, 220 parents (110 parents with autistic and 110 parents with normal children) were selected. Data collection was done using the Enrich Marital Satisfaction Scale and Oxford Happiness Questionnaire. The Mann-Whitney and independent t-tests were used for data analysis.

Results: The obtained results showed that in all components of marital satisfaction and happiness, except for conflict resolution, parents of normal children had significantly higher scores than the parents of children with autism $(\mathrm{P}<0.05)$.

Discussion: According to the results, there is a possible relationship between the autism disorders of children and their marital satisfaction and their parents' happiness.

\section{* Corresponding Author:}




\section{Highlights}

- The satisfaction of family members is one of the most important factors influencing the effective functioning of a family.

- Having a child with autism can significantly affect the families, especially the parents; their mothers have lower mental health and marital satisfaction.

\section{Plain Language Summary}

The parents of children with autism compared with the parents of normal children, constantly engage in problems with their children, instead of thinking about issues that improve their lives. This study was aimed at investigating the effects of having an autistic child on their parents' marital satisfaction and happiness and comparing it with those having a normal child. The obtained results indicated a relationship between the autism disorders of children and their parents' marital satisfaction and happiness.

\section{Introduction}

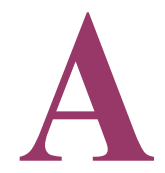

utism is a neurological disorder that begins early in childhood. In autism, the central nervous system fails to correctly manage social behaviors and communication skills, and the child is seriously in trouble to learn how to communicate and interact with others [1]. Autistic children have many behavioral problems, such as stereotyped behaviors, repression, self - stimulation, aggression, and trait parotitis [2], emotion-related disorders and problems [3], motor skills problems, especially delicate movements of hands, daily activities of life, and playing games [4]. These children suffer from natural language learning and imitation problems [5].

The prevalence of autism in children is rising. According to the reports by the Centers for Disease Control and Prevention (CDC), today, approximately 1 out of 150 children has autism and its prevalence in Iranian fiveyear-old children was reported 6.26 per 10,000 children [6]. It can be predicted that many parents of autistic children have mental health problems [7].

Autism is one of the most commonly occurring abnormalities that occur before the age of 36 months and is usually diagnosed between the ages of 2 and 5 [8]. When parents are informed that they have an autistic child, they will be frustrated with fear and disbelief. They first have to deal with the unpleasant fact that they have to deal with their children until the end of their lives and also they should adjust their expectations to their limits [9]. The lack of understanding of the evolutionary problems in these children, limited progress, and other related problems can lead to tension and emotional and behav- ioral problems in parents [10] leading to reduce the family functioning [11]. According to Volcumar and Pauls, about $85 \%$ of the children with autism have limited ability to live independently due to cognitive or adaptive constraints, due to which parents spend a lot of time to meet their children's needs during their lives [12].

The satisfaction of the family members (especially couples' satisfaction) is one of the most important factors influencing the effective functioning of a family, [13]. Marital satisfaction and quality of life are considered as the most important indicators of marital life in several studies, either alone or in combination [14]. Marital satisfaction can be defined as a mental interpretation of individuals about the general nature of marriage, which reflects a level of expectations of individuals from marriage and common life [15]. Having a child with autism would significantly affect the families, especially the parents so that the parents of these children showed a lower level of marital satisfaction and relationship and family compatibility than the control group $[16,17]$.

The results of a clinical interview to determine the coping patterns or responses and attitudes of the parents of these children showed that parents, especially mothers had lower mental health and marital satisfaction, and most cases reported the views of people about their children very important. They also felt guilty and often blamed themselves for the problem of their childhood, and use this way of thinking like a defensive strategy [18]. In addition to marital satisfaction as an essential component in the mental health of couples, having a sense of happiness as a positive emotional phenomenon is essential for humans, which gives meaning to life and 
is an effective and preparatory strategy for solving the issues ahead [19].

The term "happiness" has some psychological concepts, such as happiness, pleasure, and cheerfulness, however, it does not mean baseless optimism and deception, denial of reality, and ignoring the problems of yourself or others. Therefore, some psychologists use the general concept of "mental happiness", which includes evaluations, such as life satisfaction, emotion, positive mood, and lack of depression and anxiety [19].

Although happiness, as one of the positive emotions among psychological factors, is directly related to mental health and life satisfaction, according to studies, the presence of a disable and an exceptional child can cause negative psychologycal impacts, such as depression and loss of positive emotions, like happiness in parents [20]. Dundi Vanya and Abdo (2005) showed that the mental health and happiness of mothers of disabled children were significantly lower than the normal group [21].

The results of Iranian studies on happiness among parents with disabled children showed that the parents of these children received a lower score using scales measuring happiness than the other parents $[22,23]$. On the other hand, having a child with autism negatively affects parenting relationships, but most of the couples continue their marital lives and even state that having a child with disability reinforced their relationships, however, they had certain difficulties [24]. Therefore, contradictory results have been reported regarding the satisfaction and relationships between parents with autistic children and further relevant studies are needed.

Accordingly, it is clear that the parents of children with autism endure severe stress and have specific needs at each level. Although several studies have been conducted in Iran on autism, a limited number of studies have been done on the quality of life and marital satisfaction of parents of autistic children. This research aimed at studying the effects of the presence of an autistic child on marital satisfaction and happiness of their parents and comparing them with the parents of normal children.

\section{Methods}

Society, sample and sampling method

The present descriptive-analytic study was conducted on all couples with autistic and normal children referring to the health centers, rehabilitation centers, and schools for autism or normal children's homes in Tehran. The sample size was calculated 220 individuals using the Cochran formula at the level of $5 \%$ and confidence level of $85 \%$, as well as the unlimited population size. Accordingly, 220 parents (110 parents with autistic children and 110 parents with normal children) were selected . Both groups were matched in terms of education, paternal age, gender, and age of the child. Data was collected using the Enrich Marital Satisfaction Scale developed by Fowers and Olson (1989) and the Oxford Happiness Questionnaire (OHQ) by Michael Argyle (2009).

The inclusion criteria were having a child under 12 years of age, having an autistic child, nine other types of diseases, no serious physical and psychological disorders in parents, no consumption of psychiatric drugs by parents.

\section{Research tool}

\section{Enrich marital satisfaction scale (short form)}

This questionnaire has been used as a valid research tool in numerous clinical trials and studies. Fowers and Furz and Ellson and Olson used this questionnaire to examine marital satisfaction and believed that this scale is sensitive to changes in the family. They used random sampling in a national research on 5039 couples. Using this questionnaire, it is possible to distinguish between happy and unpleasant couples with an accuracy of 8595\%. Each item in this questionnaire assesses the key areas affecting marital relationship, by which the potential problems of the couples and their weaknesses and strengths can be measured. This scale consists of four subscales and 35 items that can be used as a research tool to measure marital satisfaction, communications , conflict resolution, and idealistic distortion. It examines marital relationships, ideal distortion, marital satisfaction, personality issues, communication, conflict resolution, financial management, leisure activities, sex, children and parenting, family and friends, egalitarian roles, male and female religious orientation, couple's relationships, and changes in marital quality.

The alpha coefficient of the questionnaire for marital satisfaction, communication, conflict resolution, and idealized distortion were $0.86,0.80,0.88$, and 0.83 , respectively. The test-retest reliability of the scale for each subtest were $0.86,0.81,0.90$, and 0.92 in Iran. Also, the alpha coefficient of the questionnaire in a research (2010) on 365 couples ( 730 subjects) was obtained as with 0.68 (with deletion of question number 24 alpha becomes $0.78), 0.78,0.62$ and 0.77 , respectively. It is a five-choice questionnaire, which is scored on a fivepoint Likert scale 
ranging from $1=$ totally agree, $2=$ agree, $3=$ not agree not disagree, $4=$ disagree, and $5=$ totally disagree.

\section{Oxford happiness questionnaire}

This questionnaire was developed by Michael Argyle in 1989 based on the Beck Depression Inventory (BDI; 1976). OHQ comprises 29 items each involving the selection of one of four options, of which 20 items were added from the BDI and 9 items added to cover other aspects of mental health. The original version of the OHQ was scored on a 4-point scale, and the revised type was set to be scored on a 6-point scale. This version has been used in Iran. The following seven factors were obtained by factor analysis: positive cognition, social commitment, positive mood, sense of control, physical health, self-satisfaction, and psychological consciousness.. Each item is scored from 0 to 3 , and the minimum score is 0 and the maximum is 87. Argyle et al. using Cronbach's alpha coefficient have reported the reliability of OHQ as 0.90 and also 0.77 a result of administering after four weeks.

Its concurrent validity of 0.43 was established ratings by friends. Arjil et al. (1989) have measured the construct validity of the scale in terms of positive emotion, satisfaction, and negative effect on the education as $32 \%, 57 \%$, and $52 \%$, respectively. Its correlation was calculated with Argyle's Life Satisfaction Index (0.57) and the BDI $(-0.52)$. Alipour and Agah Harris (2007) to verify the validity and reliability of the OHQ (developed by Argyle, 2001) teste in on a sample of 142 men and 227 women from all employees and students living in Tehran province aged $18-53$ years (mean age $=25$ years). An examination of the internal consistency of the OHQ showed that all 29 items were highly correlated with the total score.

Cronbach's alpha for the whole index was 0.91. The Pearson correlation between the OHQ and the BDI and the sub-scales of extraversion and neuroticism of the Eysenck Personality Questionnaire were respectively $-0.48,-0.45$, and -0.36 , confirming their convergent and divergent validity Factor analysis extracted 5 factors of life satisfaction, self-esteem, subjective well-being, selfsatisfaction, and positive affect with an eigenvalue of greater than one that could explain $49.7 \%$ of the total variance. The average score of Iranian subjects on the OHQ ( $M=42.07)$ was different from the findings by Argyle's study ( $\mathrm{M}=6.35)$. Based on the findings, $\mathrm{OHQ}$ is an appropriate tool to measure happiness in Iranian society.

\section{Procedure}

After making the necessary coordination and obtaining permissions from the Tehran University of Social Welfare and Rehabilitation Sciences to refer the centers and clinics and autistic schools in Tehran, and considering ethical considerations and expressing the research objectives, the informed consent was obtained from the studied parents and students to participate in this research. Then the questionnaires were distributed among the parents of autistic children. They were asked to read the questions carefully and select the responses according to their characteristics and do not leave the questions unanswered if possible. At the same time, the parents were assured of the confidentiality of their information and providing the results only to the individuals and institutions with their written consent. A total of 110 questionnaires were distributed among parents of children who had no disorders and had a good level of mental health. Finally, the data were analyzed through SPSS v. 22 using the Man-Whitney U-test and Independent t-test.

\section{Results}

As shown in Tables 1 and 2, the mean scores of parents with normal children were higher than that of the parents of autistic children in terms of happiness and marital satisfaction $(\mathrm{P}<0.05)$.

Regarding the components of marital satisfaction, except for conflict resolution, the mean scores of parents with normal children was significantly higher than that of those with autistic children $(\mathrm{P}<0.05)$. To compare marital satisfaction, communication, conflict resolution, idealized distortion, and satisfaction in two groups, the Man-Whitney test was used and the results are reported in Table 2.

There was a significant difference between the mean scores of both groups in communication, ideal definition,

Table 1. Comparison of the happiness in two studied groups using independent $t$-test

\begin{tabular}{|c|c|c|c|c|c|}
\hline Variable & Groups & Mean \pm SD & Av. Difference & $\mathbf{T}$ & $\mathbf{P}$ \\
\hline \multirow{3}{*}{ Happiness } & Parents of autistic children & $41 / 65 \pm 12 / 55$ & \multirow{3}{*}{$-9 / 04$} & \multirow{3}{*}{$-5 / 291$} & \multirow{3}{*}{$0 / 000$} \\
\hline & & & & & \\
\hline & Parents of normal children & $50 / 69 \pm 12 / 61$ & & & \\
\hline
\end{tabular}


Table 2 Comparison of marital satisfaction, communication, conflict resolution, idealized distortion and satisfaction in two studied groups using the Mann-Whitney test

\begin{tabular}{|c|c|c|c|c|}
\hline Variables & Parents Group & Mean Rank & z & $\mathbf{P}$ \\
\hline Marital satisfaction & $\begin{array}{l}\text { autistic children } \\
\text { normal children }\end{array}$ & $\begin{array}{l}98 / 27 \\
105 / 31\end{array}$ & $-4 / 24$ & $0 / 000$ \\
\hline Relationship & $\begin{array}{l}\text { autistic children } \\
\text { normal Children }\end{array}$ & $\begin{array}{l}110 / 26 \\
102 / 36\end{array}$ & $-3 / 17$ & $0 / 002$ \\
\hline Conflict resolution & $\begin{array}{l}\text { autistic children } \\
\text { normal children }\end{array}$ & $\begin{array}{l}111 / 2 \\
106 / 74\end{array}$ & $-0 / 526$ & $0 / 599$ \\
\hline Idealized distortion & $\begin{array}{l}\text { autistic Children } \\
\text { normal children }\end{array}$ & $\begin{array}{l}103 / 95 \\
114 / 47\end{array}$ & $-3 / 6$ & $0 / 000$ \\
\hline Satisfaction & $\begin{array}{l}\text { autistic children } \\
\text { normal children }\end{array}$ & $\begin{array}{c}123 / 98 \\
142\end{array}$ & $-7 / 65$ & $0 / 000$ \\
\hline
\end{tabular}

Iranian Rehabilitation Dourna

and marital satisfaction $(\mathrm{P}=0.05)$. Therefore, there was a significant relationship between having a normal and autistic child, the quality of marital satisfaction, and parental happiness. Accordingly, having a child with autism can affect the satisfaction and happiness of the couples.

\section{Discussion}

Parents of children with autism face difficulties leading to high risk of psychological problems and outcomes. This study aimed at comparing and rate of satisfaction and happiness in two groups of parents with autistic and normal children in Tehran. The obtained findings showed a significant difference between the components of happiness and satisfaction in the two groups. These results are consistent with the findings of Higgins et al. [16], Blanchard et al. [10], Jalali Moghadam and Pour Etemadi [17], Tonali et al. [18], and Khariri-Hassan and Taghvaee [22]. Based on these results, the presence of a child with a disability and a specific need in a family leads to the problems in the various dimensions of the parents' marital satisfaction and happiness.

For explaining the findings of the present study, it can be admitted that one of the biggest concerns of the parents of autistic children, as a lifelong disorder, is being concerned about the child's future. They are worried that their child will not be cured and people will not understand the special conditions such children are facing with. Autistic children and their parents have reported negative reactions and the lack of favorable social sup- port [25]. In most societies, the children don't learn to take on the responsibility themselves (especially they are dependent to their mothers), therefore, in families with a disabled child, parents face a lot of worries. Also, the parents of autistic children compared with those with normal children, are constantly engaged in their problems resulting from the complications of autism, instead of thinking about the issues improving their lives.

Accordingly, they may be unaware of their physical and psychological health and can also be affected by various illnesses, especially mental disorders [26]. On the other hand, these parents feel embarrassed or have limited communication with others, which can lead to hidden anger. Some of them often have to spend additional expenses for the treatment and education of their children. Also, these children need special care and services [12]. Therefore, such parents live in an anxietyprovoking situations, in which the needs of parents are ignored and the overall quality of life of these parents is affected. In such conditions, their marital satisfaction is reduced, which confirms our results.

The presence of a disabled or exceptional child can lead to psychological difficulties, such as depression and loss of positive emotions, such as happiness. In addition, happiness, as one of the positive emotions among other psychological factors, is directly associated with mental health and life satisfaction [20]. Moreover, Tunali and Power have found that many mothers of these children are forced to leave their work and stay at home due to 
their children's problems. They also have lowest amount of leisure time, which is the main reason for a reduction in affection and happiness among them $[18,22]$. Sleep disturbances, physical disability, lack of social interactions, reduced sexual relations, marital and financial problems, lack of enough time to spent on health issues, and long-term exposure to chronic stress also affect the quality of life in parents of autistic children [27, 28].

In the present study, the mean scores of the components of marital satisfaction, such as communication, idealized distortions, and marital satisfaction, except for the conflict resolution were significantly different between two groups. According to Roloff and Ifert (2000), some couples manage conflicts through avoidance and withdrawal. They also believed that avoidance behaviors associated with negative emotions lead to a more reduction in marital satisfaction than neutral avoidance [29]. Therefore, many couples attempt to deny and suppress their conflict because they are unaware of the correct ways of expressing their feelings and resolving conflicts.

The limited number of male subjects, as well as unwillingness to participate in the study were the limitations of this research. In addition, using self-report questionnaires asking personal questions from couples likely affected the valid responses by the participants and they are not representative of their real conditions. According to the obtained results indicating that the presence of children with autism can almost affect the quality of their parents' relationships, especially marital satisfaction and happiness, it is suggested that providing supportive services and educational programs can be effective in improving the quality of marital relationships.

\section{Conclusion}

According to our results, the presence of a mentally retarded children, especially children with autism, can affect the marital satisfaction of their parents more than other disorders. It is suggested to provide supportive services and educational programs to improve the quality of marital relationships in parents with autistic children.

\section{Ethical Considerations}

\section{Compliance with ethical guidelines}

There was no ethical considerations to be considered in this research.

\section{Funding}

This article was extracted from research project in Deputy of Research and Technology Student Research Committee, University of Social Rehabilitation and Welfare Sciences.

\section{Authors' contributions}

Methodology: Hosein Hoseinnejad, Farhad Chopaniyan; Invesigation: Asghar Dadkhah; Writing the original draft: Hosein Hoseinnejad, Farhad Chopaniyan, Omid Sarvi Moghanlo, Mohammad Rostami; Writing a review and editing: Asghar Dadkhah, Mohammad Rostami; Funding acquisition: Hosein Hoseinnejad, Asghar Dadkhah; Resources: Farhad Chopaniyan, Hosein Hoseinnejad, Omid Sarvi Moghanlo; Supervision: Asghar Dadkhah.

\section{Conflict of interest}

The author declared no conflict of interests.

\section{Acknowledgments}

The authors are grateful to the participants in this research. This research was extracted from the research project approved by the student committee of the University of Social Welfare and Rehabilitation Sciences.

\section{References}

[1] Fombonne E. The prevalence of autism. JAMA. 2003; 289(1):87-9. [DOI:10.1001/jama.289.1.87] [PMID]

[2] Khoramabadi R, Pouretemad HR, Tahmasian K, Chimeh $\mathrm{N}$. [A comparative study of parental stress in mothers of autistic and non autistic children (Persian)]. Journal of Family Research. 2009; 5(19):387-99.

[3] Rapin I. Autistic children: Diagnosis and clinical features. Pediatrics. 1991; 87(5):751-60.

[4] Restall G, Magill-Evans J. Play and preschool children with autism. American Journal of Occupational Therapy. 1994; 48(2):113-20. [DOI:10.5014/ajot.48.2.113] [PMID]

[5] Sevlever M, Gillis JM. An examination of the state of imitation research in children with autism: Issues of definition and methodology. Research in Developmental Disabilities. 2010; 31(5):976-84. [DOI:10.1016/j.ridd.2010.04.014] [PMID]

[6] Samadi SA, Mahmoodizadeh A, McConkey R. A national study of the prevalence of autism among fiveyear-old children in Iran. Autism. 2012; 16(1):5-14 [DOI:10.1177/1362361311407091] 
[7] Carter AS, Martínez-Pedraza FdL, Gray SA. Stability and individual change in depressive symptoms among mothers raising young children with ASD: Maternal and child correlates. Journal of Clinical Psychology. 2009; 65(12):1270-80. [DOI:10.1002/jclp.20634] [PMID]

[8] Zander E. Introduktion om autism [Internet]. 2004[Cited 2020Apr12.] Available from: http://habilitering.se/sites/ habilitering.se/files/introduktion_om_autism_engelska.pdf

[9] Bradford R. Children, families, and chronic disease: Psychological models and methods of care. London: Routledge; 1997. [DOI:10.4324/9780203287842] [PMCID]

[10] Blanchard LT, Gurka MJ, Blackman JA. Emotional, developmental, and behavioral health of American children and their families: A report from the 2003 National Survey of Children's Health. Pediatrics. 2006; 117(6):e1202-12. [DOI:10.1542/ peds.2005-2606] [PMID]

[11] Pisula E. Parents of children with autism: Recent research findings. Psychiatria polska. 2002; 36(1):95-108.

[12] McCracken JT, McGough J, Shah B, Cronin P, Hong D, Aman MG, et al. Risperidone in children with autism and serious behavioral problems. New England Journal of Medicine. 2002; 347(5):314-21. [DOI:10.1056/NEJMoa013171] [PMID]

[13] Sinha S, Mukerjee N. Marital adjustment and personal space orientation. The Journal of Social Psychology. 1990; 130(5):6339. [DOI:10.1080/00224545.1990.9922955]

[14] Funk JL, Rogge RD. Testing the ruler with item response theory: Increasing precision of measurement for relationship satisfaction with the Couples Satisfaction Index. Journal of Family Psychology. 2007; 21(4):572-83. [DOI:10.1037/08933200.21.4.572] [PMID]

[15] Dizjani F, Kharamin S. [Reality therapy effect on marital satisfaction and women's quality of life. Armaghane-danesh (Persian)]. 2016; 21(2):187-99.

[16] Higgins DJ, Bailey SR, Pearce JC. Factors associated with functioning style and coping strategies of families with a child with an autism spectrum disorder. Autism. 2005; 9(2):125-37. [DOI:10.1177/1362361305051403] [PMID]

[17] Jalali-Moghadam N, Pouretemad H, Sedghpor B, KhoShabi $\mathrm{K}$, Chimeh N. [Parents of children with pervasive developmental disorders and their coping strategies (Persian)]. Journal of Family Research. 2008; 3(4)761-74

[18] Tunali B, Power TG. Coping by redefinition: Cognitive appraisals in mothers of children with autism and children without autism. Journal of Autism and Developmental Disorders. 2002; 32(1):25-34. [DOI:10.1023/A:1017999906420] [PMID]

[19] Seligman ME. Authentic happiness: Using the new positive psychology to realize your potential for lasting fulfillment. New York: Simon and Schuster; 2004.

[20] Piqueras JA, Kuhne W, Vera-Villarroel P, Van Straten A, Cuijpers P. Happiness and health behaviours in Chilean college students: A cross-sectional survey. BMC Public Health. 2011; 11(1):443. [DOI:10.1186/1471-2458-11-443] [PMID] [PMCID]

[21] Duvdevany I, Abboud S. Stress, social support and wellbeing of Arab mothers of children with intellectual disability who are served by welfare services in northern Israel. Journal of Intellectual Disability Research. 2003; 47(4-5):264-72. [DOI:10.1046/j.1365-2788.2003.00488.x] [PMID]
[22] Khariri-Hassan M, Taghvaee D. Comparison between aggression and anxiety among child labor with and without sexual child abuse. Journal of Pediatric Nursing. 2016; 3(2):10-5. [DOI:10.21859/jpen-03022]

[23] Maryami N, Ahmadian H. Effectiveness of patience education on Mental Welfare and the reduction in the Stress of the Mothers of Mentally Disable Children in Qorveh County. International Journal of Humanities and Cultural Studies. 2016; 1570-82.

[24] Walsh CE, O'Leary DK. A comparative study of the marital relationship between parents with children with autism and those with children without autism. Good Autism Practice. 2013; 14(1):28-33.

[25] Mansell W, Morris K. A survey of parents' reactions to the diagnosis of an autistic spectrum disorder by a local service: Access to information and use of services. Autism. 2004; 8(4):387-407. [DOI:10.1177/1362361304045213] [PMID]

[26] Lloyd T, Hastings R. Hope as a psychological resilience factor in mothers and fathers of children with intellectual disabilities. Journal of Intellectual Disability Research. 2009; 53(12):957-68. [DOI:10.1111/j.1365-2788.2009.01206.x] [PMID]

[27] Taylor ZE, Larsen-Rife D, Conger RD, Widaman KF, Cutrona $C E$. Life stress, maternal optimism, and adolescent competence in single mother, African American families. Journal of Family Psychology. 2010; 24(4):468-77. [DOI:10.1037/ a0019870] [PMID] [PMCID]

[28] Mallers MH, Charles ST, Neupert SD, Almeida DM. Perceptions of childhood relationships with mother and father: Daily emotional and stressor experiences in adulthood. Developmental Psychology. 2010; 46(6):1651-61. [DOI:10.1037/ a0021020] [PMID] [PMCID]

[29] Roloff ME, Ifert DE. Conflict management through avoidance: Withholding complaints, suppressing arguments, and declaring topics taboo. Balancing the Secrets of Private Disclosures. 2000; 151-79. 
This Page Intentionally Left Blank 